\title{
AN EVALUATION OF THE CONTRIBUTION OF THE SPECIALIST PALLIATIVE CARE NURSING SERVICE TO PATIENT CARE IN AN ACUTE HOSPITAL SETTING.
}

\author{
Michael Connolly ${ }^{1}$; Mary Ryder ${ }^{1}$; Eileen Furlong루 Kate Frazer ${ }^{1}$; Eileen Carruthers²; Eileen McGuigan²; Teresa Plaza \\ Escribano ${ }^{1}$, Philip Larkin ${ }^{1}$; Project Steering Group ${ }^{2}$ \\ 1: University College Dublin; 2: Regional Specialist Palliative Care Services, Louth Meath Cavan Monaghan
}

Poster presented at the $16^{\text {th }}$ World Congress of the European Association for Palliative Care. P02 - 398

\section{Background \& Aims}

- In Ireland Specialist Palliative Care (SPC) is a consultant led service provided in a range of settings with Clinical nurse specialists (CNS) providing specialist care particularly in the hospital setting(i). Nurses often work independently, and are a reference point for clinical advice, care and discharge planning and family support. In Ireland five core competences have been identified for the role of CNS: clinical, advocacy, consultation, education, audit and research(ii).

- The aim of the study was to evaluate the contribution of the Specialist Palliative Care Clinical Nurse Specialist (SPCCNS) service to patient care in an acute hospital.

\section{Methodology}

A validated questionnaire survey was adopted for use to assess current understanding and contribution of the SPCCNS service. 200 questionnaires were circulated to medical, nursing and allied health care professional staff working in an acute hospital. 121 completed questionnaires were returned representing a response rate of $60.5 \%$. Responses were received from a range of health care professionals.

\section{Findings}

The majority (99.2\%) of respondents were aware that a SPCCNS service is provided at the hospital. To date $54 \%$ ( $n=65$ ) of respondents indicated that they had referred patients to the SPCCNS service. The majority of referrals sought advice on symptom management and discharge planning. Findings indicate that respondents identify clinical, advocacy and consultancy as the most important core competences. Audit and research were measured as least important aspects of the SPCCNS role, particularly by non-nursing staff. It is also worth noting that the education role of the SPCCNS was viewed as important by nurses, but was not seen as an important part of the SPCCNS service by other health care professionals.

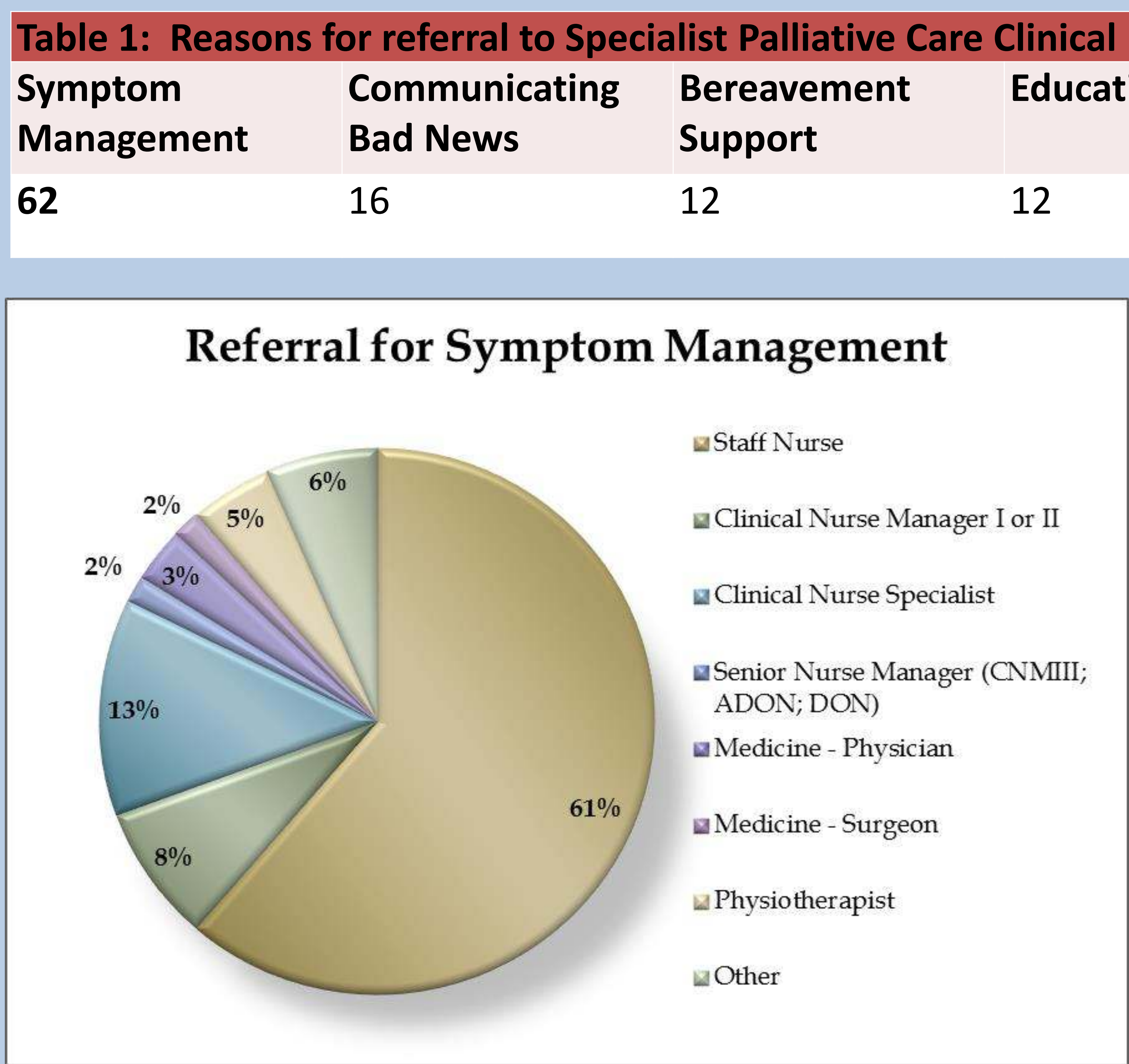

Table 2: Core competences of the CNS role - Ranked in order of importance

\section{Frequency Percent (\%)}

(n)

\begin{tabular}{|lrrr|}
\hline Clinical & 79 & 65.3 & 65.3 \\
\hline Advocacy & 25 & 20.7 & 86.0 \\
\hline Consultation & 12 & 9.9 & 95.9 \\
\hline Audit & 2 & 1.7 & 97.5 \\
\hline Research & 3 & 2.5 & 100.0 \\
\hline Total & 121 & 100.0 & \\
\hline
\end{tabular}

\begin{tabular}{ll}
$\begin{array}{l}\text { Discharge } \\
\text { Planning }\end{array}$ & Other \\
\hline 39 & 3
\end{tabular}

21 